\title{
VITAMIN D SUPPLEMENTATION IN CHILDREN AND YOUTH WITH EPILEPSY - THE EFFECT ON ORAL HEALTH CONDITION
}

\author{
Agnieszka Skawińska-Bednarczyk, Maria Mielnik-Błaszczak, Artur Michałowski, Justyna Pietrak \\ Chair and Department of Pediatric Dentistry, Medical University of Lublin, Poland
}

\begin{abstract}
INTRODUCTION: A balanced diet and supply of vitamins and minerals are important for proper functioning of each organism. Huge impact of adequate vitamin D supply on health aspects is increasingly emphasized. People with epilepsy are at risk of vitamin D deficiency.

ОвјестіVEs: The objective of the study was to assess a correlation between vitamin D supplementation in children and adolescents with epilepsy and an occurrence of carious disease and periodontal lesions.

MATERIAL AND METHODS: Both, a survey and clinical study were conducted on 107 people, aged 6-18 years with epilepsy. The questionnaire contained 15 questions about sex, respondent's age, place of residence, and vitamin D supplementation. Clinical studies were performed with the aid of headlamp and diagnostic instruments used in dentistry.

RESULTS: Vitamin D was administered during infancy in $100 \%$ of respondents. Continuous supplementation at a later age was used in $58.88 \%$ of participants. According to questionnaire study, controlled testing of vitamin D blood concentration was carried out by a pediatrician or family doctor only in $24.3 \%$ of patients. In the static analysis, in the group of people constantly receiving vitamin $\mathrm{D}$, significantly lower values of indices regarding caries intensity, periodontal diseases, and calculus deposition were found. he sensitivity, specificity, and accuracy generally increased with decreasing voxel size. Positive and negative predictive values increased with decreasing voxel size and increasing defect size.

Conclusions: Confirmed prevalence of vitamin D deficiency among children and adolescents require an improvement of principles of prevention or adopting the concept of performing routine diagnostic tests in risk groups. We predict that vitamin D supplementation increases vitamin D concentration in blood and affects the intensity of caries disease in examined group of children and adolescents with epilepsy. There is a correlation between cholecalciferol administration and periodontal treatment needs in examined group of children and adolescents with epilepsy.
\end{abstract}

KEY wORDs: children, vitamin D, epilepsy, dental caries, youth.

J Stoma 2020; 73, 6: 302-307

DOI: https://doi.org/10.5114/jos.2020.101877

\section{INTRODUCTION}

A balanced diet and vitamins and minerals supply are important for the proper functioning of each organism.
The huge impact of adequate vitamin D supply on health aspects is increasingly emphasized [1]. The major supplementation of vitamin $\mathrm{D}$ (cholecalciferol) is obtained by endogenous route during exposure to sunlight. Ultra-

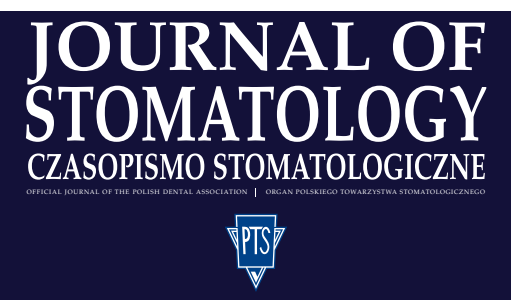

AdDRESS FOR CORRESPONDENCE: Dr. Agnieszka Skawińska-Bednarczyk, Chair and Department of Pediatric Dentistry, Medical University of Lublin, 6 Doktora Witolda Chodźki St., 20-093 Lublin, Poland, e-mail: agnieszka.skawinska@gmail.com

RECEIVED: 03.06.2020 • ACCEPTED: 27.09.2020 • PUBLISHED: 30.12.2020 
violet from the sun inducts conversion of 7-dehydrocholesterol into vitamin $\mathrm{D}_{3}$. In the liver, vitamin $\mathrm{D}_{3}$ is changed to 25 -hydroxyvitamin $\mathrm{D}$ and after that, it is metabolized to 1a, 25-hydroxyvitamin D in the kidneys (active metabolite) [2,3]. Exogenous food supply is a poorer source [3].

The production of vitamin $\mathrm{D}$ depends on many factors, including the degree of skin pigmentation, intensity of ultraviolet radiation, the degree of sun exposure, body weight, exposed body surface, cloudiness, air pollution, age, the use of cosmetics with a filter) [3].

Vitamin D plays a key role in many functions of the body. It participates in the maintenance of calcium and phosphate homeostasis, inhibits the secretion of parathyroid hormone, is an essential factor in the proper development of skeleton, has an anti-fracture properties, and affects non-specific and humoral immunity $[2,3]$. The effect on the cardiovascular system and the relationship between various cancers have been confirmed $[3,4]$.

Vitamin D deficiencies have an impact on the nervous system and mental state [3]. Excess or deficiency contributes to skin diseases [5]. Vitamin D deficiencies can also be caused by kidney or liver diseases or various chronic inflammations [3]. Vitamin D level should be especially monitored in chronically ill people, including epilepsy. Vitamin $\mathrm{D}_{3}$ plays an important role in the human brain and nervous system, and it is involved in neuroprotection brain cell proliferation and differentiation as well as brain development [6]. Moreover, the presence of vitamin $\mathrm{D}_{3}$-specific receptors and enzymes in neurons and glial cells of the brain, in the spinal cord, and in the peripheral nervous system, support the neurological role of Vitamin $\mathrm{D}_{3}$. Vitamin $\mathrm{D}_{3}$ 's anticonvulsant action in the brain is increasingly considered, and the proposed mechanisms of action are generally categorized as either genomic or non-genomic [6]. Research results available indicate that the level of vitamin D can influence the occurrence of seizures in drug-resistant epilepsy and even inhibit them $[6,7]$.

Studies conducted since the 1960 s prove that the use of antiepileptic drugs has a negative effect on bone metabolism, leading to qualitative changes in bones and thus, increasing the risk of fractures. Taking antiepileptic drugs predisposes patients to the group of increased risk of vitamin D deficiency [7].

Health of oral cavity reflects the state of the entire body. Vitamin D deficiency has a significant impact on oral health. This should be noted especially in chronically ill people who are particularly susceptible to pathological changes within the oral cavity $[5,8]$.

Dental caries and periodontal disease are associated with vitamin D deficiency and its pathophysiologic processes [9]. The mechanism of vitamin D effect on oral health is not based only on bone metabolism. Caries and abnormalities in tooth tissue mineralization are much more common in people with vitamin D deficiency [5].

Vitamin D plays a huge role in odontogenesis. The formation and mineralization of enamel is a process that can be disturbed by several metabolic factors, in which vitamin D deficiency can have a clear impact. Enamel is formed in the early stages of tooth development and is almost completely formed at the moment of its cutting. For the development of enamel, the pre-birth period, the first 10 months of life (milk and permanent teeth), the preschool and junior school (permanent teeth) periods are of key importance [10].

Vitamin D deficiency can cause teeth hypomineralization. Hypomineralized dentition is susceptible to fracture and dental caries [9].

Vitamin D also affects the absorption of mineral substances, among other phosphates, which increase the enamel resistance to acids produced by cariogenic bacteria, and thus to their demineralization effects [11]. It also affects the absorption of calcium, which improve the strength of the teeth and surrounding tissue [11].

Vitamin D deficiency affects periodontal health. Scientific research have shown that low levels of vitamin D has led to increased gum bleeding and periodontitis [12]. This should be particularly noted in patients on antiepileptic drugs that adversely affect the supporting tissues of teeth [13]. Deficiency of vitamin D is connected to a worse periodontal health and can be related to immune mechanism of periodontal infection [9].

\section{OBJECTIVES}

The objective of the study was to assess the correlation between vitamin D supplementation in children and adolescents with epilepsy and the occurrence of carious disease and periodontal lesions.

\section{MATERIAL AND METHODS}

The clinical and questionnaire examinations were conducted among a group of 107 children and young people with epilepsy of both sexes, between 6 and 18 years of age, inhabiting the Lublin macro-region. The consent for the study was obtained, and the study was approved by Research Ethics Board of the Medical University of Lublin. Participants' privacy and human rights were respected. The questionnaire was intended for parents or guardians of the children and adolescents, and was distributed among them in schools or care institutions. The questionnaire contained 15 questions about sex, respondent's age, place of residence (big city, small town, village), hygienic habits, and vitamin D supplementation.

Clinical examinations were performed with the aid of a headlamp and diagnostic instruments used in dentistry (mirror, dental probe) by earlier registered dentists.

The clinical examination evaluated:

- average numbers of D, M, F, and average number of DMFT of the studied population including vitamin D supplementation; 


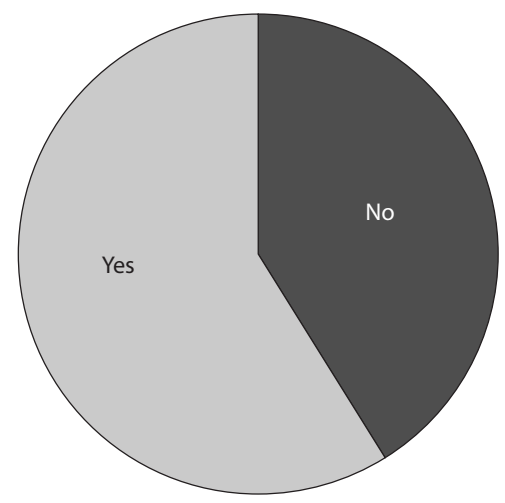

FIGURE 1. Supplementation of vitamin D

- simplified dental plaque (debris index simplified, DI-S) and tartar (calculus index simplified, CI-S) index, i.e., components of the simplified oral hygiene index (OHI-S);

- community periodontal index of treatment needs (CPITN): periodontological treatment needs indicator.

DMFT numbers indicated the sum of teeth affected by caries disease (D), teeth removed due to caries (M), and filled (F) teeth [14]. Green and vermillion OHI-S consists of two indicators: dental plaque index (DI-S) and calculus index (CI-S). Higher index values indicate the presence of a larger amount of tarnish and/or tartar. Calculation of the periodontal treatment needs index CPITN involves observing bleeding gums, tartar, and measuring gingival pouch. Its higher values indicate pathological changes within the supporting structures of the teeth [14].

The obtained results were statistically analyzed. The measurable values of parameters were described using an application of average and standard deviation values, whereas for non-measurable parameters, a cardinality and a percentage were employed. The normality of disintegration of the analyzed parameters was assessed for the measurable features using Shapiro-Wilk test. For comparing two independent groups, Mann-Whitney's test was applied, and for comparing more than two groups, Kruskal-Wallis test was used.

The value of statistically significant differences or relations was established as $p<0.05$. Database and statistical examinations were conducted using STATISTICA 8.0 (StatSoft, Poland) computer software.

\section{RESULTS}

Vitamin D was administered during infancy (under 1 year of age) in $100 \%$ of the respondents. Continuous supplementation at a later age was used in $58.88 \%$ $(n=63)$ of children (Figure 1). Vitamin D concentration tests in the blood were controlled by a general practitioner only in $24.3 \%(n=26)$ of the respondents.

Statistical analysis showed that CPITN value was significantly higher among these participants, in whom

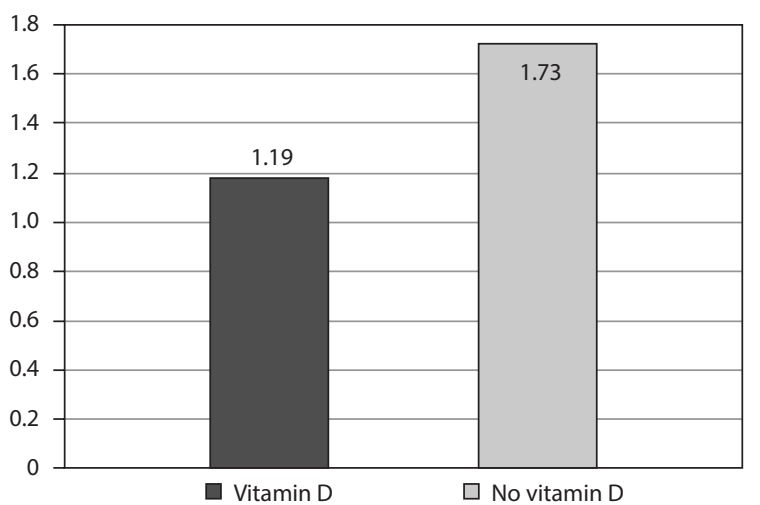

FIGURE 2. Community periodontal index of treatment needs (CPITN) values

TABLE 1. The dependence of community periodontal index of treatment needs (CPITN) on various factors

Factors Average $\begin{gathered}\text { Standard } \\
\text { deviation }\end{gathered}$
\begin{tabular}{|l|c|c|c|}
\hline Sex \\
\hline Female & 1.63 & 0.65 & $Z$ \\
\hline Male & 1.37 & 0.57 & \\
\end{tabular}

Anti-epileptic medicines

\begin{tabular}{l|l|l|l|}
\hline Yes & 1.68 & 0.60 & $Z$ \\
\cline { 1 - 3 } No & 0.96 & 0.29 &
\end{tabular}

Place of residence

\begin{tabular}{l|l|l|l}
\hline Family home & 1.62 & 0.61 & \multirow{2}{*}{$Z=2.12 ; p=0.03^{*}$} \\
\cline { 1 - 2 } Care center & 1.00 & 0.39 &
\end{tabular}

Regular dental check-up

\begin{tabular}{l|l|l|l}
\hline Yes & 1.03 & 0.54 & \multirow{2}{*}{$Z=-2.75 ; p=0.006^{*}$} \\
\cline { 1 - 3 } No & 1.71 & 0.55 &
\end{tabular}

Type of toothbrush

\begin{tabular}{l|c|c|c}
\hline Electric & 1.03 & 0.30 & \multirow{2}{*}{$Z=3.11 ; p=0.002^{*}$} \\
\cline { 1 - 2 } Manual & 1.70 & 0.61 &
\end{tabular}

Vitamin $D_{3}$ supplementation

\begin{tabular}{l|l|l|l|}
\hline Yes & 1.19 & 0.59 & $Z$ \\
\cline { 1 - 3 } No & 1.73 & 0.55 &
\end{tabular}

vitamin $\mathrm{D}$ was not administered $(1.73, p=0.02)$. Those who were taking vitamin $\mathrm{D}$ supplementation had a CPITN of 1.19 (Figure 2). The dependence of CPITN index on various factors is presented in Table 1.

DI-S index in the whole study group was on an average level of $1.79 \pm 0.70$, while CI-S was $0.43 \pm 0.52$. It was found that the patients who did not take vitamin D had a higher calculus index (0.66) compared to the examined children who were continuously given the vitamin $(0.27, p=0.000008)$. No relationship was found in the value of DI-S debris indicator. The dependence of DI-S and CI-S index on various factors is shown in Tables 2 and 3. 
TABLE 2. The dependence of debris index simplified (DI-S) on various factors

\begin{tabular}{|c|c|c|c|}
\hline Factors & Average & $\begin{array}{l}\text { Standard } \\
\text { deviation }\end{array}$ & Statistical analysis \\
\hline \multicolumn{4}{|l|}{ Sex } \\
\hline Female & 1.77 & 0.76 & \multirow[t]{2}{*}{$Z=0.21 ; p=0.83$} \\
\hline Male & 1.81 & 0.65 & \\
\hline \multicolumn{4}{|c|}{ Anti-epileptic medicines } \\
\hline Yes & 1.94 & 0.66 & \multirow[t]{2}{*}{$Z=-3.39 ; p=0.0007^{*}$} \\
\hline No & 143 & 0.67 & \\
\hline \multicolumn{4}{|l|}{ Place of residence } \\
\hline Family home & 1.75 & 0.68 & \multirow[t]{2}{*}{$Z=-1.42 ; p=0.15$} \\
\hline Care center & 1.97 & 0.75 & \\
\hline \multicolumn{4}{|c|}{ Regular dental check-up } \\
\hline Yes & 1.48 & 0.66 & \multirow[t]{2}{*}{$Z=-3.12 ; p=0.002^{*}$} \\
\hline No & 1.93 & 0.67 & \\
\hline \multicolumn{4}{|l|}{ Type of toothbrush } \\
\hline Electric & 1.53 & 0.75 & \multirow[t]{2}{*}{$Z=3.16 ; p=0.002^{*}$} \\
\hline Manual & 1.94 & 0.63 & \\
\hline \multicolumn{4}{|c|}{ Vitamin D supplementation } \\
\hline Yes & 1.72 & 0.81 & \multirow[t]{2}{*}{$Z=-0.75 ; p=0.46$} \\
\hline No & 1.90 & 0.48 & \\
\hline
\end{tabular}

TABLE 4. The dependence of $D$ index on various factors

\begin{tabular}{|c|c|c|c|}
\hline Factors & Average & $\begin{array}{l}\text { Standard } \\
\text { deviation }\end{array}$ & Statistical analysis \\
\hline \multicolumn{4}{|l|}{ Sex } \\
\hline Female & 3.62 & 3.29 & \multirow[t]{2}{*}{$Z=0.17 ; p=0.86$} \\
\hline Male & 3.67 & 4.09 & \\
\hline \multicolumn{4}{|c|}{ Anti-epileptic medicines } \\
\hline Yes & 4.36 & 4.15 & \multirow{2}{*}{$Z=3.02 ; p=0.003^{*}$} \\
\hline No & 1.90 & 1.47 & \\
\hline \multicolumn{4}{|l|}{ Place of residence } \\
\hline Family home & 3.32 & 3.12 & \multirow[t]{2}{*}{$Z=-1.55 ; p=0.12$} \\
\hline Care center & 5.16 & 5.72 & \\
\hline \multicolumn{4}{|c|}{ Regular dental check-up } \\
\hline Yes & 2.21 & 2.13 & \multirow[t]{2}{*}{$Z=-2.69 ; p=0.007^{*}$} \\
\hline No & 4.28 & 4.13 & \\
\hline \multicolumn{4}{|l|}{ Type of toothbrush } \\
\hline Electric & 1.77 & 1.78 & \multirow{2}{*}{$Z=4.39 ; p=0.00001^{*}$} \\
\hline Manual & 4.72 & 4.15 & \\
\hline \multicolumn{4}{|c|}{ Vitamin D supplementation } \\
\hline Yes & 3.35 & 4.22 & \multirow[t]{2}{*}{$Z=2.15 ; p=0.03^{*}$} \\
\hline No & 4.07 & 2.94 & \\
\hline
\end{tabular}

TABLE 3. The dependence of calculus index simplified (Cl-S) on various factors

\begin{tabular}{|c|c|c|c|}
\hline Factors & Average & $\begin{array}{l}\text { Standard } \\
\text { deviation }\end{array}$ & Statistical analysis \\
\hline \multicolumn{4}{|l|}{ Sex } \\
\hline Female & 0.56 & 0.57 & \multirow[t]{2}{*}{$Z=2.07 ; p=0.04^{*}$} \\
\hline Male & 0.33 & 0.46 & \\
\hline
\end{tabular}

\begin{tabular}{|l|l|l|l|}
\hline \multicolumn{3}{|l|}{ Anti-epileptic medicines } \\
\cline { 1 - 3 } Yes & 0.56 & 0.55 & $Z$ Z $=-4.60 ; p=0.000001^{*}$ \\
\hline No & 0.10 & 0.18 & \\
\hline
\end{tabular}

\begin{tabular}{|c|c|c|c|}
\hline \multicolumn{4}{|l|}{ Place of residence } \\
\hline Family home & 0.42 & 0.50 & \multirow[t]{2}{*}{$Z=0.22 ; p=0.83$} \\
\hline Care center & 0.46 & 0.62 & \\
\hline
\end{tabular}

Regular dental check-up

\begin{tabular}{l|l|l|l}
\hline Yes & 0.34 & 0.43 & \multirow{2}{*}{$Z$} \\
\cline { 1 - 2 } No & 0.47 & 0.55 &
\end{tabular}

Type of toothbrush

\begin{tabular}{|c|c|c|c|}
\hline Electric & 0.08 & 0.14 & \multirow[t]{2}{*}{$Z=5.66 ; p<0.000001^{*}$} \\
\hline Manual & 0.63 & 0.55 & \\
\hline \multicolumn{4}{|c|}{ Vitamin D supplementation } \\
\hline Yes & 0.27 & 0.45 & \multirow[t]{2}{*}{$Z=-4.48 ; p=0.000008^{*}$} \\
\hline No & 0.66 & 0.52 & \\
\hline
\end{tabular}

TABLE 5. The dependence of $M$ index on various factors

\begin{tabular}{|c|c|c|c|}
\hline Factors & Average & $\begin{array}{l}\text { Standard } \\
\text { deviation }\end{array}$ & Statistical analysis \\
\hline \multicolumn{4}{|l|}{ Sex } \\
\hline Female & 0.55 & 1.47 & \multirow{2}{*}{$Z=2.13 ; p=0.03^{*}$} \\
\hline Male & 0.13 & 0.43 & \\
\hline \multicolumn{4}{|c|}{ Anti-epileptic medicines } \\
\hline Yes & 0.24 & 0.54 & \multirow{2}{*}{$Z=0.38 ; p=0.71$} \\
\hline No & 0.52 & 1.75 & \\
\hline \multicolumn{4}{|l|}{ Place of residence } \\
\hline Family home & 0.39 & 1.14 & \multirow{2}{*}{$Z=1.39 ; p=0.16$} \\
\hline Care center & 0.00 & 0.00 & \\
\hline \multicolumn{4}{|c|}{ Regular dental check-up } \\
\hline Yes & 0.12 & 0.33 & \multirow{2}{*}{$Z=-0.64 ; p=0.52$} \\
\hline No & 0.41 & 1.23 & \\
\hline \multicolumn{4}{|l|}{ Type of toothbrush } \\
\hline Electric & 0.00 & 0.00 & \multirow{2}{*}{$Z=2.27 ; p=0.02^{*}$} \\
\hline Manual & 0.50 & 1.28 & \\
\hline \multicolumn{4}{|c|}{ Vitamin D supplementation } \\
\hline Yes & 0.29 & 1.25 & \multirow{2}{*}{$Z=2.36 ; p=0.02^{*}$} \\
\hline No & 0.36 & 0.65 & \\
\hline
\end{tabular}


The number of DMFT in the examined group of children was 6.18. Studies showed that the average value of D in the examined group of children with epilepsy was 3.64 , whereas for $\mathrm{M}$, the average was 0.32 , and for $\mathrm{F}$ it was 2.21. Statistically significant differences were noted in the group of participants, who were constantly supplemented with vitamin $\mathrm{D}$, involving the number of teeth affected by caries (D) and the number of teeth removed due to caries (M). The average value of $\mathrm{D}$ in the examined group of children with epilepsy was 3.64. Significantly lower D-index was presented in patients who had vitamin D (3.35) compared to the examined children who had no vitamin D administered (4.07, $p=0.03$ ). The value of the $\mathrm{M}$ number was significantly higher in people who were not supplemented with vitamin $\mathrm{D}(0.36, p=0.02)$ compared to those taking cholecalciferol (0.29). The dependence of $\mathrm{D}, \mathrm{M}$, and F index is presented in Tables 4-6.

\section{DISCUSSION}

The relationship between vitamin $\mathrm{D}$ concentration in the body and the oral cavity state of health is increasingly observed [12, 15-17]. Administration of vitamin D to infants in Poland is recommended by a team of experts to all newborns and infants [16]. In the study group, vitamin D was administered to infants (under 1 year of age) in $100 \%$ of respondents. It should be noted that people with nervous system diseases, such as epilepsy, are included in the risk group of vitamin D deficits. In these groups, supplementation should be carried out under the control of blood concentration [16]. According to questionnaire study, the control of vitamin D blood concentration was carried out by a pediatrician or family doctor only in $24.3 \%(n=26)$ of the patients.

According to experts' recommendations, when it is not possible to assess the level of vitamin D concentration, dosing should be prescribed as for the rest of population [16]. In countries with similar location as Poland, the supplementation is recommended to everyone. In the examined group, the permanent supplementation at a later age was used in $58.88 \%(n=63)$ of the patients.

Statistical analysis showed that the CPITN value was significantly higher, and thus the periodontal condition was worse among the patients who had no vitamin $\mathrm{D}$ administration $(1.73, p=0.02)$. Those who took vitamin $\mathrm{D}$ had a CPITN of 1.19 . The relationship between vitamin D concentration and periodontal health can be caused by the impact of cholecalciferol on the immune system and bone homeostasis [13]. There is divergent data in literature regarding the correlation between vitamin $\mathrm{D}$ concentration and periodontal disease $[12,13,17]$. Our research found a correlation between a deposition of calculus and vitamin D supplementation. It was observed that the patients who did not take vitamin D had a higher plaque index (0.66) compared to the examined children with continuous administration of vitamin $\mathrm{D}(0.27$, $p=0.000008)$. Increased tartar buildup in people not
TABLE 6. The dependence of $F$ index on various factors

\begin{tabular}{|c|c|c|c|}
\hline Factors & Average & $\begin{array}{l}\text { Standard } \\
\text { deviation }\end{array}$ & Statistical analysis \\
\hline \multicolumn{4}{|l|}{ Sex } \\
\hline Female & 2.43 & 3.91 & \multirow{2}{*}{$Z=0.53 ; p=0.60$} \\
\hline Male & 2.05 & 3.52 & \\
\hline \multicolumn{4}{|c|}{ Anti-epileptic medicines } \\
\hline Yes & 2.21 & 3.98 & \multirow{2}{*}{$Z=-0.78 ; p=0.43$} \\
\hline No & 2.23 & 2.87 & \\
\hline \multicolumn{4}{|l|}{ Place of residence } \\
\hline Family home & 2.51 & 3.95 & \multirow{2}{*}{$Z=1.45 ; p=0.15$} \\
\hline Care center & 0.84 & 1.38 & \\
\hline \multicolumn{4}{|c|}{ Regular dental check-up } \\
\hline Yes & 3.97 & 5.07 & \multirow{2}{*}{$Z=2.69 ; p=0.007^{*}$} \\
\hline No & 1.43 & 2.54 & \\
\hline \multicolumn{4}{|l|}{ Type of toothbrush } \\
\hline Electric & 3.03 & 5.27 & \multirow{2}{*}{$Z=0.93 ; p=0.35$} \\
\hline Manual & 1.75 & 2.26 & \\
\hline \multicolumn{4}{|c|}{ Vitamin D supplementation } \\
\hline Yes & 2.21 & 3.87 & \multirow{2}{*}{$Z=1.14 ; p=0.25$} \\
\hline No & 2.23 & 3.45 & \\
\hline
\end{tabular}

taking vitamin D may be due to disorders of enamel development, which are caused by too low cholecalciferol levels during the formation of tooth tissue $[17,18]$.

Analysis of research results showed statistically significant differences in the group of people in whom vitamin $\mathrm{D}$ was constantly supplemented. The average number of teeth affected by caries (D) in the examined group of children with epilepsy was 3.64. Significantly lower D-index included patients with vitamin D supplementation (3.35) compared to the children who did not have vitamin $\mathrm{D}$ administered $(4.07, p=0.03)$. The value of the number of teeth removed $(\mathrm{M})$ due to caries was significantly higher in the patients who were not given vitamin $\mathrm{D}(0.36, p=0.02)$ compared to those taking cholecalciferol (0.29). The anti-caries effect may result from the effect of vitamin D on the formation of normal, demineralization-resistant enamel. The induction of defensins and cathelicidin may also be important [17].

A similar relationship regarding caries and vitamin $\mathrm{D}$ concentration was shown by Schroth et al. [15]. They found that children with higher levels of cholecalciferol had lower values of caries disease indicators. Supplementation of cholecalciferol and its prophylactic effect on caries was also verified in studies by Marshal et al. and Hujoel $[15,18]$.

\section{CONCLUSIONS}

Confirmed prevalence of vitamin D deficiency among children and adolescents would require improving the 
principles of prevention or adopting the concept of performing routine diagnostic tests in all risk groups. We predict that vitamin $\mathrm{D}$ supplementation increases vitamin $\mathrm{D}$ concentration in blood and affects the intensity of caries in the examined group children and adolescents with epilepsy. There is a correlation between cholecalciferol administration and periodontal treatment needs in the investigated group of children and adolescents with epilepsy.

\section{CONFLICT OF INTEREST}

The authors declare no potential conflicts of interest with respect to the research, authorship, and/or publication of this article.

\section{References}

1. Al Khalifah R, Hudairi A, Al Homyani D, Harnad MH, Bashiri FA. Vitamin D supplementation to prevent vitamin D deficiency for children with epilepsy. Medicine 2018; 97: e12734.

2. Teagarden DL, Meador KJ, Loring DW. Low vitamin D levels are common in patients with epilepsy. Epilepsy Res 2014; 108: 1352-1356.

3. Gawryś J, Gawryś K, Doroszko A. Seasonal changes of vitamin D concentration and their impact on its supplementation. Kosmetologia Estetyczna 2016; 6: 561-566.

4. Pittas AG, Chung M, Trikalinos T, et al. Vitamin D and cardiometabolic outcomes: a systematic review. Ann Intern Med 2010; 5: 307-314.

5. Gadomski A. The effects of vitamin D deficiency in human organism. Nowa Pediatria 2017; 1: 34-37.

6. Pendo K, DeGiorgio CM. Vitamin D3 for treatment of epilepsy: basic mechanisms, animal models, and clinical trials. Front Neurol 2016; 7: 218

7. Hallo A, Clemens Z, Kamondi A, Lakatos P, Szucs A. Correction of vitamin $D$ deficiency improves seizure control in epilepsy: a pilot study. Epilepsy Behav 2012; 24: 131-133.

8. Abou-Eladab E, Shehata F, Albahari S. Vitamin D deficiency and associated dental caries. IJOAR 2016; 5: 1239-1246.

9. Botelho J, Machado V, Proenca L, Delgdo AS, Mendes JJ. Vitamin $\mathrm{D}$ deficiency and oral health: a comprehensive review. Nutrients 2020; 12 : 1471.

10. Karwat ID, Kołłątaj W, Kołłątaj B, Piątkowska A, Piecewicz-Szczęsna A. Clinical and laboratory signs of vitamin D deficiency in children and adolescents with a dental caries. Probl Hig Epidemiol 2013; 94: 122-129.

11. Parthasarathy P, Priya V, Gayathri R. Relationship between vitamin D and dental caries - review. J Pharm Sci Res 2016; 8: 459-460.

12. Dietrich T, Nunn M, Dawson-Hughes B, et al. Association between serum concentration of 25-hydroxyvitamin $\mathrm{D}$ and gingival inflammation. Am J Clin Nutr 2005; 82: 575-580.

13. Bonnet C, Rabbani R, Moffatt MEK, Kelekis-Cholakis A, Schroth RJ. The relation between periodontal disease and vitamin D. J Can Dent Assoc 2019; 84: j4.

14. Marya CM. Dental indices. In: A Textbook of Public Health Dentistry. $1^{\text {st }}$ ed. Jaypee Brothers Medical Publishers Pte Ltd.; 2011, pp. 185-211.

15. Schroth RJ, Rabbani R, Loewen G, Moffatt ME. Vitamin D and dental caries in children. J Dent Res 2016; 95: 173-179.

16. Rusińska A, Płudowski P, Walczak M, et al. Vitamin D supplementation guidelines for Poland - a 2018 update. Postępy Neonatologii 2018; 24: 1-24.

17. Alshouibi EN, Kaye EK, Cabral HJ, Leone CW, Garcia RI. Vitamin $D$ may reduce periodontal disease prevalence in older men. J Dent Res 2013; 92: 689-693.

18. Hujoel PP. Vitamin D and dental caries in controlled clinical trials: systematic review and meta-analysis. Nutr Rev 2013; 71: 88-97. 